\title{
Ischaemic brain damage in the gerbil in the absence of "no-reflow'
}

\author{
DAVID E. LEVY, ${ }^{2}$ JAMES B. BRIERLEY, AND FRED PLUM \\ From the Department of Neurology, the New York Hospital-Cornell Medical Center, New York, U.S.A., and the \\ Medical Research Council Laboratories, Woodmansterne Road, Carshalton, Surrey, England
}

SYNOPSIS Approximately $40 \%$ of gerbils subjected to one hour of unilateral carotid artery occlusion displayed neurological abnormalities during that time. Most such animals were subsequently found to have ischaemic neuronal alterations within the territory of the ipsilateral middle cerebral artery. In contrast, impaired reperfusion ('no-reflow') rarely occurred and cannot therefore be implicated in the pathogenesis of ischaemic brain damage.

Ames and his co-workers (Ames et al., 1968; Cantu et al., 1969) observed in rabbits that periods of cerebral ischaemia (circulatory arrest) of more than five minutes were followed by multifocal deficits in brain reperfusion as assessed by the post-ischaemic, intra-arterial injection of a suspension of carbon black. These zones of non-perfusion increased in number and size with increasing length of ischaemia, and it was concluded that 'no-reflow' resulting from ischaemic vascular damage was an important factor preventing the recovery of the brain parenchyma after ischaemia. This conclusion, that the vessels of the brain rather than its neurones are initially vulnerable to ischaemia, diverges sharply from long-held concepts about the effects of hypoxia on the brain. Furthermore, the zones of 'no-reflow' in their initial experiments did not conform with the distribution of neuropathological alterations in most studies of circulatory arrest and other types of ischaemia.

In a rat preparation of cerebral hypoxiaischaemia (Levy et al., 1975a), impaired reperfusion or 'no-reflow' was rare and not important

\footnotetext{
1 Read in part before the 51st annual meeting of the American Association of Neuropathologists, 30 May 1975. Supported in part by Fellowship grants from the New York Heart Association and grant No. NS 2218-01 from the National Institute of Neurological Disease and Stroke (Dr Levy) and by Stroke Center grant No. NS 3346 from the National Institute of Neurological Disease and Stroke.

2 Address for reprint requests: Dr D. E. Levy, New York HospitalCornell Medical Center, 525 East 68th Street, New York, N.Y. 10021 , U.S.A.

(Accepted 11 July 1975.)
}

for the development of brain damage. There was also a close correlation between the clinical state and the neuropathology in the early postischaemic period. However, the model was complicated and did not produce severe ischaemia (Salford and Siesjö, 1974) so that another model was required in which the role of 'no-reflow' in ischaemic brain damage could be investigated.

The gerbil is a useful animal for the study of cerebrovascular disease because permanent unilateral common carotid artery occlusion produces ipsilateral brain damage in about half the animals (Levine and Payan, 1966; Kahn, 1972; Harrison et al., 1973). This susceptibility to ischaemia is probably due to the presence of only limited collateral channels, including those between the carotid and vertebrobasilar arterial systems (Levy and Brierley, 1974). After permanent occlusion, however, 'no-reflow' cannot be assessed nor can optimal perfusion-fixation be obtained for neuropathological examination. In addition, since most such brain-damaged gerbils die (Kahn, 1972), the relationship between clinical state and brain damage during prolonged survival cannot be evaluated.

For these reasons, a model of transient regional cerebral ischaemia in the gerbil has been developed that produces brain damage in a high proportion of animals, permits prolonged clinical observation, and allows perfusion of the brain with fixatives or with indicators of vas- 
cular patency. This model has yielded no evidence to show that 'no-reflow' contributes significantly to ischaemic brain damage. Furthermore, a high correlation between behavioural abnormalities and brain damage suggests that this model may be useful in the study of other aspects of the pathogenesis and treatment of stroke.

\section{METHODS}

UNILATERAL CAROTID ARTERY OCCLUSION Mature male gerbils (50-70 g) were anaesthetized with either divinyl ether or halothane $(1-2 \%)$. The right common carotid artery was exposed through a ventral midline skin incision, and the artery, isolated from related nerves and vessels, was occluded with a small aneurysm clip. Interruption of flow was verified visually and the incision was closed. The duration of anaesthesia was always under three minutes. Gerbils exposed to comparable anaesthesia in a sham operation without carotid occlusion invariably displayed normal motor behaviour within three minutes after anaesthesia.

In 80 animals subjected to transient carotid occlusion (Table 1), the clip was left in place for one hour.

TABLE 1

EXPERIMENTAL GROUPS

\begin{tabular}{cr}
\hline Transient common carotid artery occlusion & 80 \\
Infusion of carbon black & 25 \\
Died (at 8, 10, and $48 \mathrm{~h}$ ) & 3 \\
Neuropathological examination & 52 \\
Survival '0' & 14 \\
Survival $\geqslant 6 \mathrm{~h}$ & 38 \\
\hline Permanent common carotid artery occlusion \\
(neurological examination only)
\end{tabular}

The animals were then reanaesthetized, and the incision was reopened. After verification that the carotid blood flow was still interrupted, the clip was removed, flow was restored, and the incision was closed. This procedure lasted less than two minutes. All but three animals that died spontaneously were subsequently prepared for neuropathological or vascular study. In a further 13 animals, the clip was left in place. These animals were observed for five days, but not studied further.

NeUrological examination Power and tone were difficult to assess in gerbils with unilateral carotid artery occlusion but other motor abnormalities were more easily recognized. (1) Abnormal gait When gait was asymmetrical, gerbils were unable to walk out of a circle of $50 \mathrm{~cm}$ radius within 30 seconds, even when their tails were pinched. (2) Diminished responsiveness Some gerbils did not move in response to stroking or noise, and others lost the righting reflex. (3) Seizures Either focal or generalized seizures were noted.

NEUROPATHOLOGICAL EXAMINATION Fifty-two gerbils surviving transient carotid artery occlusion were killed by perfusion-fixation with formalinglacial acetic acid-absolute methanol $(1: 1: 8 ;$ FAM). After thoractomy under anaesthesia and intracardiac injection of heparin (100 international units), a 20-gauge metal cannula was inserted through the left ventricle and secured in the root of the ascending aorta. Perfusion with physiological saline at a pressure of $120 \mathrm{mmHg}$ was begun immediately, the right atrium was opened, and the descending aorta was clamped. After one minute of perfusion with saline, FAM was perfused at the same pressure for 20 to 30 minutes (total volume 75 to $100 \mathrm{ml}$ ). The brain was left in situ for at least four hours before removal into FAM. After separation of the hindbrain at the intercollicular level, the cerebral hemispheres were cut coronally into an anterior slice including the corpus striatum and a posterior slice including the hippocampus and thalamus. A parasagittal slice was taken from the hindbrain. Blocks were embedded in a paraffin and plastic polymer (Paraplast), and sections cut at $7 \mu \mathrm{m}$ and $12 \mu \mathrm{m}$ were stained with cresyl fast violet, cresyl fast violet and luxol fast blue, phosphotungstic acid haematoxylin, and haematoxylin and eosin. Neuropathological examination was made by J.B.B. without knowledge of the individual experimental protocol. The quality of perfusion-fixation was judged as good in all animals because of white colour, firm consistency, and absence of blood in vessels. Shift of midline structures was determined from examination of slices and microscopic sections.

VASCULAR REPERFUSION In 25 gerbils subjected to transient carotid artery occlusion, the right external jugular vein was first cannulated so that carbon black could be injected after removal of the clip. At least one hour before carotid occlusion, animals were anaesthetized with halothane $(1-2 \%)$, and a 26gauge Teflon catheter was introduced through a stab wound in the scalp and secured in the right external jugular vein. This procedure was carried out in less than 20 minutes and never produced any motor abnormality. The right common carotid artery was then occluded for one hour, and motor behaviour 
was observed. Five minutes after removing the clip, carbon black $(6.0 \mathrm{ml} / 100 \mathrm{~g}$ at a rate of $3.0 \mathrm{ml} / \mathrm{min})$ was injected intravenously. All animals survived the injection and were killed by decapitation after two minutes. Brains were removed into $10 \%$ formalin. Subsequently, the intact and sliced brains were examined naked-eye and with an operating microscope. The carbon black used in this experiment was prepared as previously described (Levy et al., 1975a).

\section{RESULTS}

MOTOR BEHAVIOUR Thirty-five of 80 gerbils $(44 \%)$ subjected to unilateral carotid artery occlusion exhibited motor abnormalities during the hour of occlusion. Abnormalities of gait were noted in all 35 animals. Twenty-one circled predominantly to the right, and six to the left, with no asymmetry in the remaining eight. In affected animals, the left hindlimb was sometimes abducted, and the left forelimb held under the body. Diminished responsiveness was evident in 26 gerbils. Most failed to respond to auditory stimuli, but four also lost the righting reflex. Twenty-six gerbils had focal, generalized, or rolling seizures.

Forty-one gerbils were observed after removal of the clip (Tables 1 and 2). Twenty-one remained normal during and after occlusion. Of the remaining 20,16 recovered from their motor disability within 24 hours, although five had minor residual left hindlimb weakness. One animal was killed by perfusion at six hours when it appeared moribund. Three gerbils deteriorated after a brief period of motor improvement and died spontaneously at eight, 10 and 48 hours.

Five of the 13 gerbils $(38 \%)$ subjected to permanent unilateral carotid artery occlusion showed motor abnormalities. All the affected animals died, whereas the remainder were normal during the five day period of observation.

NEUROPATHOLOGY (Table 2) Sixteen of 52 gerbils $(31 \%)$ killed by perfusion-fixation 0 to

TABLE 2

CLINICAL STATUS AND NEUROPATHOLOGY

\begin{tabular}{|c|c|c|c|c|c|c|c|c|c|c|c|c|}
\hline \multirow{3}{*}{$\begin{array}{c}\text { Animal } \\
\text { no. }\end{array}$} & \multicolumn{3}{|c|}{ Clinical status during occlusion } & \multirow[t]{3}{*}{ Survival } & \multicolumn{8}{|c|}{ Neuropathology } \\
\hline & \multicolumn{2}{|c|}{ Abnormalities of } & \multirow[b]{2}{*}{ Seizures } & & \multicolumn{2}{|c|}{ Cortex } & \multicolumn{2}{|c|}{ Hippocampus } & \multirow{2}{*}{$\begin{array}{l}\text { Stri- } \\
\text { atum }\end{array}$} & \multirow{2}{*}{$\begin{array}{l}\text { Thal- } \\
\text { amus }\end{array}$} & \multirow{2}{*}{$\begin{array}{l}\text { White } \\
\text { matter }\end{array}$} & \multirow{2}{*}{$\begin{array}{c}\text { Mid } \\
\text { line } \\
\text { shift }\end{array}$} \\
\hline & Gait & Responsiveness & & & Ant. & Post. & $H .1$ & $H .3-5$ & & & & \\
\hline $\begin{array}{c}61 \\
106 \\
126 \\
140 \\
178 \\
\text { (9 animals) }\end{array}$ & $\begin{array}{l}\text { Yes } \\
\text { Yes } \\
\text { Yes } \\
\text { Yes } \\
\text { Yes } \\
\text { No }\end{array}$ & $\begin{array}{l}\text { No } \\
\text { Yes } \\
\text { Yes } \\
\text { Yes } \\
\text { Yes } \\
\text { No }\end{array}$ & $\begin{array}{l}\text { Yes } \\
\text { Yes } \\
\text { No } \\
\text { Yes } \\
\text { Yes } \\
\text { No }\end{array}$ & $\begin{array}{l}0 \\
0 \\
0 \\
0 \\
0 \\
0\end{array}$ & $\begin{array}{l}+ \\
0 \\
0 \\
0 \\
0 \\
0\end{array}$ & $\begin{array}{l}0 \\
0 \\
0 \\
0 \\
0 \\
0\end{array}$ & $\begin{array}{l}+ \\
0 \\
0 \\
0 \\
0 \\
0\end{array}$ & $\begin{array}{l}+ \\
0 \\
0 \\
0 \\
0 \\
0\end{array}$ & $\begin{array}{l}0 \\
0 \\
0 \\
0 \\
0 \\
0\end{array}$ & $\begin{array}{l}0 \\
0 \\
0 \\
0 \\
0 \\
0\end{array}$ & $\begin{array}{l}\text { No } \\
\text { No } \\
\text { No } \\
\text { No } \\
\text { No } \\
\text { No }\end{array}$ & $\begin{array}{l}\text { No } \\
\text { No } \\
\text { No } \\
\text { No } \\
\text { No } \\
\text { No }\end{array}$ \\
\hline $\begin{array}{c}73 \\
80 \\
84 \\
85 \\
96 \\
98 \\
\text { (5 animals) }\end{array}$ & $\begin{array}{l}\text { Yes } \\
\text { Yes } \\
\text { Yes } \\
\text { Yes } \\
\text { Yes } \\
\text { Yes } \\
\text { No }\end{array}$ & $\begin{array}{l}\text { Yes } \\
\text { Yes } \\
\text { No } \\
\text { Yes } \\
\text { Yes } \\
\text { Yes } \\
\text { No }\end{array}$ & $\begin{array}{l}\text { Yes } \\
\text { Yes } \\
\text { Yes } \\
\text { Yes } \\
\text { No } \\
\text { No } \\
\text { No }\end{array}$ & $\begin{array}{l}6 \mathrm{H} \\
1 \mathrm{D} \\
1 \mathrm{D} \\
1 \mathrm{D} \\
1 \mathrm{D} \\
1 \mathrm{D} \\
1 \mathrm{D}\end{array}$ & $\begin{array}{l}+ \\
++ \\
++ \\
++++^{*} \\
++ \\
0 \\
0\end{array}$ & $\begin{array}{l}0 \\
0 \\
+ \\
++ \\
0 \\
0 \\
0\end{array}$ & $\begin{array}{l}+++ \\
+ \\
+ \\
+++ \\
0 \\
0 \\
0\end{array}$ & $\begin{array}{l}0 \\
+ \\
0 \\
+++ \\
+ \\
+ \\
0\end{array}$ & $\begin{array}{l}+++ \\
++ \\
++ \\
+++^{*} \\
++ \\
++ \\
0\end{array}$ & $\begin{array}{l}++ \\
0 \\
0 \\
++* \\
0 \\
0 \\
0\end{array}$ & $\begin{array}{l}\text { No } \\
\text { No } \\
\text { No } \\
\text { No } \\
\text { No } \\
\text { No } \\
\text { No }\end{array}$ & $\begin{array}{l}\text { Yes } \\
\text { No } \\
\text { No } \\
\text { Yes } \\
\text { Yes } \\
\text { No } \\
\text { No }\end{array}$ \\
\hline $\begin{array}{c}23 \\
24 \\
25 \\
31 \\
32 \\
35 \\
54 \\
60 \\
63 \\
76 \\
77 \\
78 \\
\text { (15 animals) }\end{array}$ & $\begin{array}{l}\text { Yes } \\
\text { Yes } \\
\text { Yes } \\
\text { Yes } \\
\text { Yes } \\
\text { No } \\
\text { Yes } \\
\text { Yes } \\
\text { Yes } \\
\text { Yes } \\
\text { Yes } \\
\text { Yes } \\
\text { No }\end{array}$ & $\begin{array}{l}\text { Yes } \\
\text { Yes } \\
\text { Yes } \\
\text { No } \\
\text { No } \\
\text { No } \\
\text { No } \\
\text { No } \\
\text { No } \\
\text { No } \\
\text { Yes } \\
\text { No } \\
\text { No }\end{array}$ & $\begin{array}{l}\text { No } \\
\text { Yes } \\
\text { Yes } \\
\text { No } \\
\text { Yes } \\
\text { No } \\
\text { Yes } \\
\text { Yes } \\
\text { Yes } \\
\text { No } \\
\text { Yes } \\
\text { No } \\
\text { No }\end{array}$ & $\begin{array}{r}5 \mathrm{D} \\
5 \mathrm{D} \\
5 \mathrm{D} \\
5 \mathrm{D} \\
5 \mathrm{D} \\
8 \mathrm{D} \\
7 \mathrm{D} \\
5 \mathrm{D} \\
5 \mathrm{D} \\
5 \mathrm{D} \\
5 \mathrm{D} \\
5 \mathrm{D} \\
5-8 \mathrm{D}\end{array}$ & $\begin{array}{l}+ \\
+ \\
+ \\
0 \\
++ \\
+ \\
+++^{*} \\
++++^{*} \\
++++^{*} \\
0 \\
0 \\
++ \\
0\end{array}$ & $\begin{array}{l}0 \\
0 \\
0 \\
0 \\
+ \\
0 \\
++ \\
+ \\
+ \\
0 \\
0 \\
++ \\
0\end{array}$ & $\begin{array}{l}++ \\
++ \\
+++ \\
0 \\
+++ \\
++ \\
+++^{*} \\
+++^{*} \\
+++^{*} \\
0 \\
0 \\
++^{*} \\
0\end{array}$ & $\begin{array}{l}0 \\
++ \\
0 \\
0 \\
+ \\
0 \\
+++ \\
+++ \\
+++ \\
0 \\
0 \\
+++ \\
0\end{array}$ & $\begin{array}{l}0 \\
+ \\
+++^{*} \\
0 \\
+++^{*} \\
++ \\
+++^{*+} \\
+++^{*} \\
+++^{*} \\
0 \\
0 \\
+++^{*} \\
0\end{array}$ & $\begin{array}{l}0 \\
0 \\
+++^{*}+ \\
0 \\
+++^{*}+ \\
0 \\
+ \\
+{ }^{*} \\
0 \\
0 \\
0 \\
++^{*} \\
0\end{array}$ & $\begin{array}{l}\text { No } \\
\text { No } \\
\text { Yes } \\
\text { No } \\
\text { No } \\
\text { No } \\
\text { Yes } \\
\text { Yes } \\
\text { Yes } \\
\text { No } \\
\text { No } \\
\text { No } \\
\text { No }\end{array}$ & $\begin{array}{l}\text { Yes } \\
\text { No } \\
\text { No } \\
\text { No } \\
\text { No } \\
\text { No } \\
\text { No } \\
\text { No } \\
\text { No } \\
\text { No } \\
\text { No } \\
\text { Yes } \\
\text { No }\end{array}$ \\
\hline
\end{tabular}

Neuronal ischaemic alterations: $0=$ none; $+=$ few; $++=$ many; $+++=$ most $;++++=$ all,

$*=$ infarction. Additional involvement of: $\dagger=$ hypothalamus; $\ddagger=$ septal region.

Three additional gerbils with abnormal gait, responsiveness, and seizures died after eight, 10 , and 48 hour survivals (see text). 


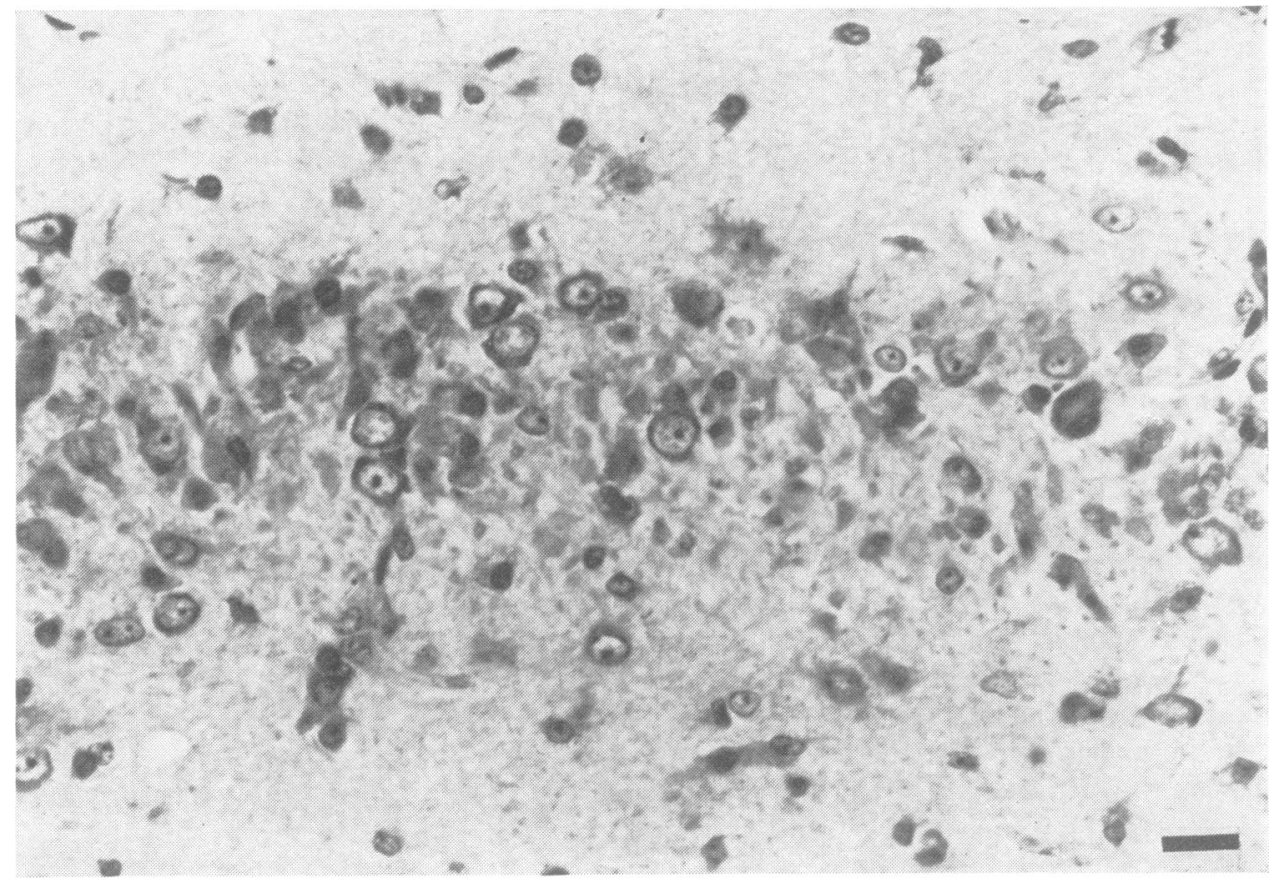

FIG. 1 Animal no. 32 (survival five days). Pyramidal cell layer of right hippocampus showing cell 'ghosts', some with and some without dark, shrunken nuclei. Paraffin, cresyl fast violet and luxol fast blue, 20 um bar.

eight days after one hour of unilateral common carotid artery occlusion exhibited structural alterations. In all such brain-damaged animals, the left cerebral hemisphere, cerebellum, and brain-stem were normal. In the right cerebral cortex, neuropathological alterations were restricted to the territory of the middle cerebral artery and were usually more marked at the anterior coronal level. The artefacts of 'dark' and 'hydropic' neurones were not seen in any animal.

In the series as a whole, the process of ischaemic neuronal damage was recognizable as a continuum extending from the earliest stage of neuronal microvacuolation (Brown and Brierley, 1968; Brierley, 1973; Levy et al., 1975a) at ' $O$ ' survival to the later stages of ischaemic cell change, homogenizing cell change, naked nuclei, and ultimately the disappearance of the neurone at about eight days. The stage of homogenizing cell change was seen after five to eight days. The cytoplasm contained no Nissl substance and was progressively less stainable with eosin and luxol fast blue (cell ' ghosts'). The nuclei remained shrunken and dark stained (Fig. 1) or broke up into more or less spherical fragments (Fig. 2).

Significant gliomesodermal reaction was confined to animals surviving five to eight days. There was no haemorrhage into leptomeninges or brain parenchyma in any animal. Infiltration of leptomeninges and perivascular spaces with lymphocytes and polymorphonuclear leucocytes was restricted to the right cerebral hemisphere in one animal surviving for five days.

Ischaemic damage attained the level of infarction in seven animals. Within the infarct, there was total destruction of neurones and glial elements, with sparing only of the larger blood vessels (Figs 3, 4).

The distribution and extent of ischaemic damage are outlined in Table 2 and described below: 


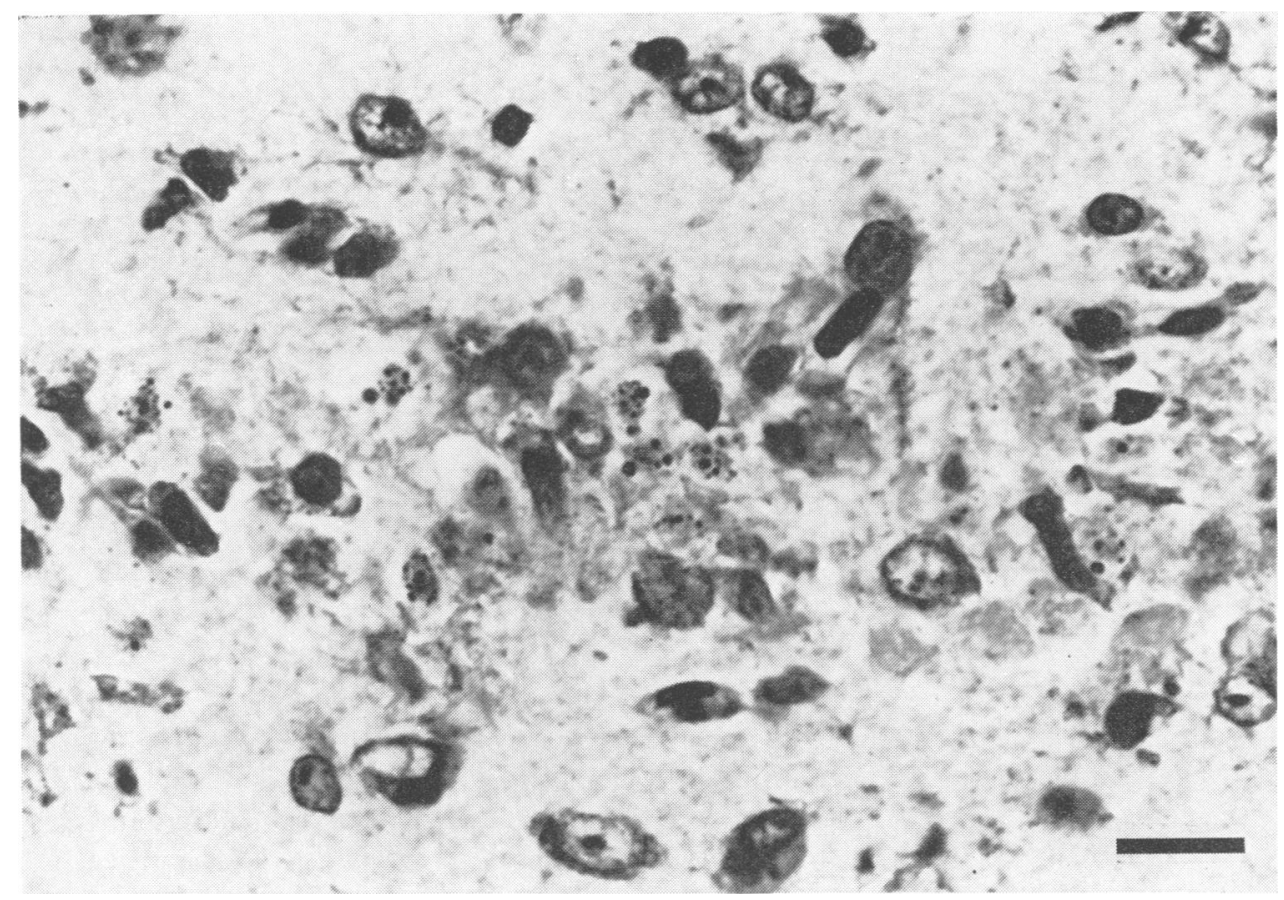

FIG. 2 Same animal as Fig. 1. Right hippocampus showing fragmentation of nuclei of pyramidal neurones. The cytoplasm is almost unstained. Paraffin, cresyl fast violet and luxol fast blue. $20 \mu \mathrm{m}$ bar.

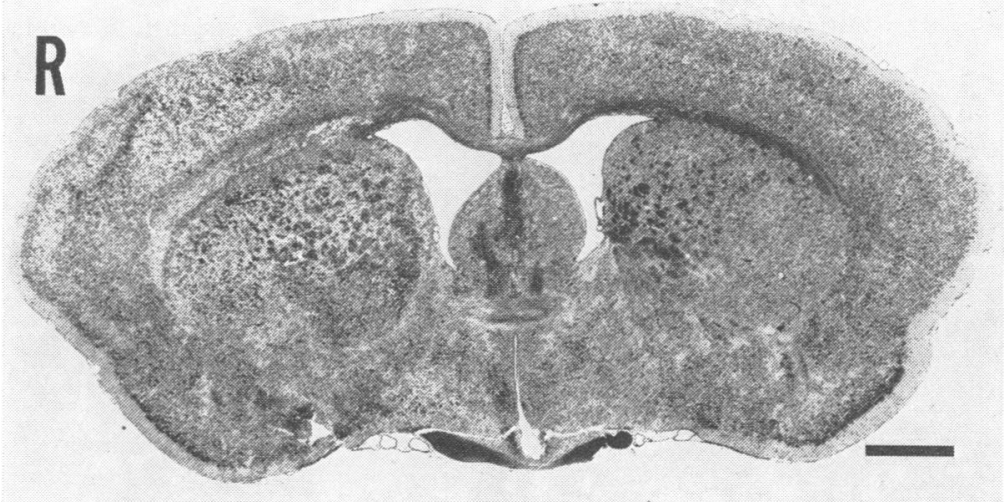

FIG. 3 Animal no. 54 (survival seven days). Coronal section at anterior level. Note infarction in right cerebral cortex (middle cerebral artery territory), striatum and callosal radiation. Paraffin, cresyl fast violet and luxol fast blue. $1 \mathrm{~mm}$ bar.

' $O$ ' survival (one animal) Macroscopic appearances of the intact and sliced brain were normal. Microscopic alterations were slight and consisted of microvacuolation in occasional neurones of cortical layers 3,5 , and 6 anteriorly and in hippocampal zones h.1 and 3-5.
Survival-six hours (one animal) On macroscopic examination there was a shift of midline structures to the left. Microscopic alterations were restricted to the right cerebral hemisphere and consisted of ischaemic cell change with and without incrustations and a few instances of 


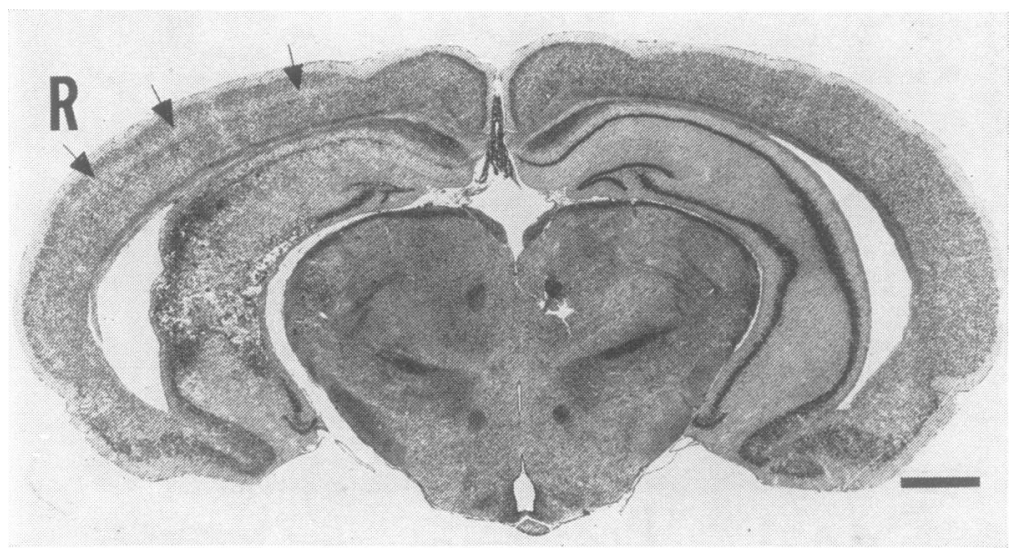

FIG. 4 Same animal as Fig. 3. Coronal section at posterior level. Note infarction in right hippocampus and near lateral border of thalamus. There is loss of neurones in the third cortical layer (arrows). Paraffin, cresyl fast violet and luxol fast blue. $1 \mathrm{~mm}$ bar.

homogenizing cell change in the cerebral cortex. There was some enlargement of astrocytic nuclei while microglia and blood vessels were normal.

Survival-one day (five animals) A shift of midline structures to the left was marked in one animal and slight in another. Ischaemic cell change with incrustations was seen in two animals, in the hippocampus of one and at the boundary zone between the anterior and the middle cerebral artery distributions in the other. Altered neurones showing homogenizing cell change were seen in the remaining damaged regions of these two animals and in the damaged regions of the other three abnormal animals. The distribution of ischaemic neurones is shown in Table 2. In one gerbil, brain damage, greatest in the entire series, included cortical infarction at the anterior level, destruction of the fascia dentata and pyramidal cell layer in the hippocampus, and infarction in the striatum and thalamus. Another animal was unique in that the cerebral cortex was normal in spite of neuronal alterations in deeper structures.

Survival-five to eight days (nine animals) Slight

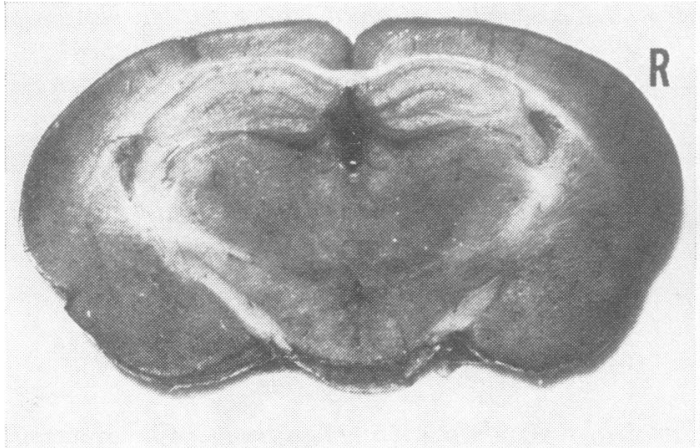

(a)

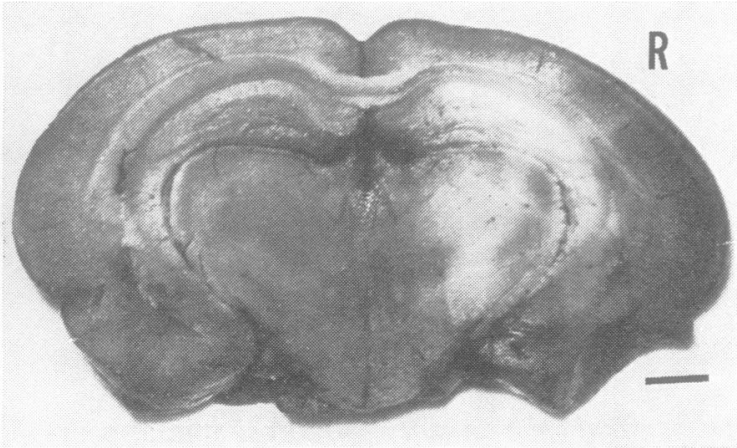

(b)

FIG. 5 Posterior coronal sections after intravenous carbon black injection. (a) Normal reperfusion as seen in 15 neurologically normal and nine neurologically impaired gerbils. (b) Pallor within the territory of the right middle cerebral artery seen in a single neurologically impaired animal. $1 \mathrm{~mm}$ bar. 
shift of midline structures to the left was present in two animals. In all nine, however, homogenizing cell change, cell ghosts, and naked nuclei were seen in all damaged regions (Figs 1, 2). When damage was restricted to neurones, as in a cortical layer or in the pyramidal cell layer of the hippocampus, astrocytes and microglia proliferated by mitotic division. Microglia gave rise, via the rod cell stage, to small numbers of lipid phagocytes. When, however, ischaemic damage attained the level of infarction (Figs 3, 4), lipid phagocytes were derived by mitotic division from adventitial cells, which were characterized by their fusiform shape and elongated nuclei containing two nucleoli. Infarcts varied from small foci in the thalamus to full thickness cortical necrosis at anterior levels. At the periphery of the infarcts, there was marked proliferation of fibrous astrocytes. In four animals, some pallor of myelin staining was seen in the callosal radiation, lateral subcortical white matter, and in the fibre bundles of the striatum.

There was evidence of cerebral swelling in the brains of the three gerbils that died before they could be perfusion-fixed. All three had an expanded right cerebral hemisphere, and the cerebellar vermis had herniated in the gerbil dying after a survival of two days. Microscopic examination of this brain showed areas of infarction in the right cortex, hippocampus, striatum and thalamus, and also neuronal loss in the right superior colliculus.

CLINICAL-PATHOLOGICAL CORRELATION This was evaluated in 52 gerbils killed by perfusionfixation after one hour of unilateral carotid artery occlusion. Only one of 30 clinically normal gerbils had ischaemic damage, whereas such damage was seen in 15 of 22 gerbils with clinical abnormalities during occlusion $\left(\mathrm{P}<0.01, \chi^{2}\right.$ test). No clinical feature during or after carotid occlusion predicted either the severity or the extent of ischaemic neuronal damage. As noted, virtually no long-term survivor of carotid occlusion was clinically abnormal at the time of perfusion-fixation, although brain damage was often extensive.

VASCULAR REPERFUSION Cerebral pallor suggesting impaired reperfusion ('no-reflow') was seen in only one of 10 gerbils with clinical abnor- malities and in none of 15 gerbils that were clinically normal (Fig. 5). In the single abnormal animal with impaired reperfusion, a large area of pallor corresponded to the distribution of the right middle cerebral artery.

\section{DISCUSSION}

Unilateral common carotid artery occlusion in the gerbil produces clinical and ischaemic abnormalities in about $40 \%$ of animals regardless of the method of occlusion or the anaesthesia used. The carotid clip applied under brief halothane anaesthesia and left in situ caused motor abnormalities in five of 13 animals, and all five subsequently died. This outcome is similar to that reported by others (Kahn, 1972; Harrison et al., 1973) after division of one carotid artery under barbiturate anaesthesia. One hour of unilateral carotid occlusion in the present series produced a $44 \%$ incidence of clinical dysfunction and a $31 \%$ incidence of ischaemic brain damage. These ratios are not significantly different ( $\chi^{2}$ test), indicating that one hour of unilateral occlusion damages the brain in the same proportion of gerbils as does permanent occlusion. The lower mortality with transient rather than permanent occlusion suggests that removing the clip permits recovery of some animals. This model thereby provides an opportunity to study events both during and after transient cerebral ischaemia.

The higher incidence of ischaemic damage in the brains of neurologically impaired gerbils fixed after at least six hours $(39 \%)$ does not necessarily imply an additional hypoxic-ischaemic stress after removal of the clip. In the Levine rat model, neuronal damage can be seen in a greater proportion of animals after a survival of 30 minutes than at the end of the hypoxicischaemic stress (Salford et al., 1973). During this additional 30 minutes, there is no systemic hypotension, no systemic hypoxia, and no impaired reperfusion (Levy et al., 1975a). After the milder stress of simple regional ischaemia in the gerbil, a brief delay in the appearance of recognizable damage would likewise be expected without implying an additional insult.

The detailed distribution of brain damage after transient unilateral carotid occlusion in gerbils is partly explained by features of the cerebro- 
vascular anatomy already described (Levine and Sohn, 1969; Levy and Brierley, 1974). Consistent paramedian cortical sparing (seen macroscopically and in coronal section) may be attributed to the common interhemispheric anterior cerebral artery. Evidently, this vessel always receives sufficient blood flow from the contralateral carotid system to supply the paramedian neocortex of both sides. Relative sparing of the posterior portion of the middle cerebral artery cortical territory may be ascribed to collateral vessels from the posterior cerebral artery which, although a branch of the internal carotid artery, nonetheless receives variable collaterals from the vertebrobasilar system. The frequency of damage in the hippocampus, striatum, and thalamus suggests that these structures derive most of their blood supply from the internal carotid arteries rather than from the vertebrobasilar circulation. Damage in the superior colliculus of one animal implies that this structure may receive blood from the posterior cerebral artery as it passes around the midbrain on to the cerebral surface.

The incidence and distribution of ischaemic alterations in gerbils with carotid occlusion depend on the adequacy of communications between the two carotid circulations anteriorly and between the carotid and vertebrobasilar circulation posteriorly. Paramedian cortical sparing in damaged brains means that even when anterior communications between the two carotid systems are functional, they are inadequate to prevent ischaemic damage in the middle cerebral artery territory. The pattern of brain damage cannot therefore be explained solely on the basis of these anterior communications as has been suggested recently by Berry et al. (1975). The consistent relative sparing of the cortex at the posterior level further underlines the functional importance of the communications between the carotid and vertebrobasilar systems (Levy and Brierley, 1974).

Gerbils that made substantial clinical recovery after carotid occlusion often had extensive ischaemic damage in cortical and subcortical regions. This dissociation between final clinical status and brain damage implies that regions containing damaged neurones or altered white matter were not essential for normal clinical function. It is likely that early and transient metabolic disturbances in ipsilateral and con- tralateral structures contributed to the initial neurological picture. Bilateral alterations in adenine nucleotides, phosphocreatine, and lactate have been reported within minutes of unilateral microsphere embolization in the rat (Kogure et al., 1974), and bilateral changes in noradrenaline and dopamine have been found in the same preparation (Kogure et al., 1975). Early bilateral changes in adenine nucleotides, lactate, and phosphocreatine have also been found in gerbils with clinical abnormalities during unilateral carotid artery occlusion (Levy et al., 1975b). Subsequent development of brain oedema may contribute to the clinical picture during the early post-ischaemic period. Harrison et al. (1973) showed that water content in the affected cerebral hemisphere was increased eight hours after permanent unilateral carotid occlusion in gerbils; in the present study, shift of midline structures consistent with brain swelling was seen in five gerbils (survival six hours to five days). Improvement in metabolic abnormalities and in brain oedema may thus correlate with clinical improvement. The persistence of brain damage without clinical signs must mean that motor control is poorly localized in the gerbil forebrain. There must be almost complete bilateral representation of function, and encephalization is likely to be even less than in the cat where forebrain section at the hypothalamic level leads to only minor impairment of gait (Hinsey and Ranson, 1928). Furthermore, clinically abnormal animals occasionally recovered and had normal brains. This observation also suggests that metabolic disturbances can cause clinical dysfunction without producing enduring structural damage.

The presence of unequivocal neurological impairment during carotid occlusion in gerbils permits confident identification of animals with damaged brains. Such animals have already been used for biochemical studies (Levy et al., 1975b) and are particularly appropriate for the assessment of therapeutic interventions. They can also be used to assess the role of 'no-reflow' in ischaemic brain damage.

The absence of 'no-reflow' in all but one clinically affected gerbil implies that 'no-reflow' was not essential for the development of ischaemic damage ranging from isolated neuronal changes to total infarction. Recent studies using 
carbon injected after middle cerebral artery clipping in squirrel monkeys support this conclusion (Little et al., 1975). The difference between these results and those of Ames probably lies in the route of carbon administration. Carbon black injected into the ascending aorta of both gerbils and rats at a pressure of $120 \mathrm{mmHg}$ results in bilateral areas of pallor in the brains of both normal and abnormal animals. This suggests that, after arterial injection of carbon black, particles may occlude cerebral vessels. Although the carbon black was filtered and allowed to stand overnight (Ames et al., 1968; Ginsberg and Myers, 1972), the possibility remains that within the vascular bed, carbon black gives rise to intravascular aggregates that are filtered in the lungs after intravenous, but in the brain after intra-arterial injection. Cantu et al. (1969) showed that a low reperfusion pressure favours the demonstration of the 'no-reflow' phenomenon. In the present experiments, intravenous injection of carbon black lowered systemic blood pressure, but 'no-reflow' was not observed. It appears doubtful that 'no-reflow' plays an important or early role in the genesis of the ischaemic brain damage that follows transient interruption of the cerebral circulation.

\section{REFERENCES}

Ames, A., III, Wright, R. L., Kowada, M., Thurston, J. M., and Majno, G. (1968). Cerebral ischemia. 2. The noreflow phenomenon. American Journal of Pathology, 52, 437-454.

Berry, K., Wísniewski, H. M., Svarzbein, L., and Baez, S. (1975). On the relationship of brain vasculature to production of neurological deficit and morphological changes following acute unilateral common carotid artery ligation in gerbils. Journal of the Neurological Sciences, 25, 75-92.

Brierley, J. B. (1973). Pathology of cerebral ischemia. In Cerebral Vascular Diseases, Eighth Conference, pp. 59-75. Edited by F. H. McDowell and R. W. Brennan. Grune and Stratton: New York.

Brown, A. W., and Brierley, J. B. (1968). The nature, distribution and earliest stages of anoxic-ischaemic nerve cell damage in the rat brain as defined by the optical microscope. British Journal of Experimental Pathology, 49, 87106.

Cantu, R. C., Ames, A., III, DiGiacinto, G., and Dixon, J. (1969). Hypotension: A major factor limiting recovery from cerebral ischemia. Journal of Surgical Research, 9, 525-529.

Ginsberg, M. D., and Myers, R. E. (1972). The topography of impaired microvascular perfusion in the primate brain following total circulatory arrest. Neurology (Minneap.), 22, 998-1011.

Harrison, M. J. G., Brownbill, D., Lewis, P. D., and Ross Russell, R. W. (1973). Cerebral edema following carotid artery ligation in the gerbil. Archives of Neurology, 28, 389-391.

Hinsey, J. C., and Ranson, S. W. (1928). A note on the significance of the hypothalamus for locomotion. Journal of Comparative Neurology, 46, 461-463.

Kahn, K. (1972). The natural course of experimental cerebral infarction in the gerbil. Neurology (Minneap.), 22, 510-515.

Kogure, K., Busto, R., Scheinberg, P., and Reinmuth, O. M. (1974). Energy metabolites and water content in rat brain during the early stage of development of cerebral infarction. Brain, 97, 103-114.

Kogure, K., Scheinberg, P., Matsumoto, A., Busto, R., and Reinmuth, O. M. (1975). Catecholamines in experimental brain ischemia. Archives of Neurology, 32, 21-24.

Levine, S., and Payan, H. (1966). Effects of ischemia and other procedures on the brain and retina of the gerbil (Meriones unguiculatus). Experimental Neurology, 16, 255-262.

Levine, S., and Sohn, D. (1969). Cerebral ischemia in infant and adult gerbils. Relation to incomplete circle of Willis. Archives of Pathology, 87, 315-317.

Levy, D. E., and Brierley, J. B. (1974). Communications between vertebro-basilar and carotid arterial circulations in the gerbil Experimental Neurology, 45, 503-508.

Levy, D. E., Brierley, J. B., Silverman, D. G., and Plum, F. (1975a). Brief hypoxia-ischemia initially damages cerebral neurons. Archives of Neurology, 32, 450-456.

Levy, D. E., Plum, F., and Duffy, T. E. (1975b). Cerebral energy metabolism during transient ischemia and recovery in the gerbil. Federation Proceedings, 34, 347.

Little, J. R., Kerr, F. W. L., and Sundt, T. M. (1975). Microcirculatory obstruction in focal cerebral ischemia. Relationship to neuronal alterations. Mayo Clinic Proceedings, 50, 264-270.

Salford, L. G., Plum, F., and Brierley, J. B. (1973). Graded hypoxia-oligemia in rat brain. 2. Neuropathological alterations and their implications. Archives of Neurology, 29, 234-238.

Salford, L. G., and Siesjö, B. K. (1974). The influence of arterial hypoxia and unilateral carotid artery occlusion upon regional blood flow and metabolism in the rat brain. Acta Physiologica Scandinavica, 92, 130-141. 